EXEMPLARIa Classica

Journal of Classical Philology

23, 2019, $\mathrm{xx}-\mathrm{xx}$

ISSN 1699-3225

\title{
AGONES POÉTICO-MUSICALES EN GRECIA: DOS NUEVOS VOLÚMENES ${ }^{1}$
}

\author{
José Antonio Fernández Delgado \\ Universidad de Salamanca \\ jafdelgado@usal.es
}

1. Numerados correlativamente y con la uniformidad (y pulcritud, todo hay que decirlo) que en general caracteriza a las publicaciones de la editorial Fabrizio Serra (Pisa/Roma) y más en este caso al tratarse en realidad de tres partes de un proyecto más amplio, en la misma línea de investigación del libro de Alessandra Manieri sobre los agones poético-musicales en Beocia (Pisa/Roma 2009), reseñado por mí en esta misma revista (Exemplaria Classica. Journal of Classical Philology 14 (2010), 329-332), acaban de ser publicados dos nuevos volúmenes de dicho proyecto, dedicado a los agones poético-musicales en Grecia Antigua. El tema es amplio y dará sin duda para más volúmenes a juzgar por la gran cantidad de material epigráfico, y en ocasiones también literario, utilizado en estos casos, y por los centros tan importantes, empezando por la propia Atenas, que restan todavía por estudiar ${ }^{2}$. Hasta el punto de que se ha creado una base de datos en curso de elaboración, Terpander, con este fin.

Aunque sin relación formal con el proyecto pero sí indicativo del interés y la actualidad del tema, también acaba de salir a la luz un grueso volumen ${ }^{3}$, resultado de un simposio celebrado en la Universidad de Perugia en 2015 en el marco de un Proyecto Internacional coordinado por dicha Universidad y del que forman también parte las Universidades de Urbino, Chieti, Salento y Messina y financiado por el Ministerio Italiano dell'Università e la Ricerca, Gli agoni poetico-musicali nella Grecia antica: fonti letterarie, storiche $e$ archeologiche, simposio en el que he tenido el honor de ser invitado a participar como miembro externo del proyecto y de formar parte del comité

${ }^{1}$ Agoni poetico-musicali nella Grecia antica: Maria Elena della Bona I pythia di Delfi, Pisa-Roma: Fabrizio Serra Editore, 2017, 305 pp., ISBN 978-88-6227-983-3; Flavio Massaro, Sparta, Pisa-Roma: Fabrizio Serra Editore, 2018, ISBN 978-88-6227-994-9.

${ }^{2}$ Sin olvidar las regiones helenizadas tras las conquistas de Alejandro, cf. F. Pordomingo, "Poesía, música y fiesta en el Egipto helenístico", Philologia, Universitas, Vita. Trabajos en honor de Tomás González Rolán (Eds. J.M. Baños Baños et alii), Madrid 2014, 773-84.

${ }^{3}$ Poeti in agone. Competizioni poetiche e musicali nella Grecia antica, a cura di A. Gostoli, A. Fongoni \& F. Biondi, GIF BIB 18, Ed. Brepols, Turnhout 2017. 
científico internacional, con una ponencia en colaboración con Francisca Pordomingo ${ }^{4}$. Un trabajo ampliamente informativo sobre la citada base de datos Terpander, a cargo del autor de uno de los dos libros ahora reseñados, se incluye precisamente en este volumen ${ }^{5}$. Y ya anteriormente la propia A. Manieri fue coorganizadora y luego coeditora de otro simposio internacional dedicado al tema, Poesia, musica e agoni nella Grecia antica, en la Universidad del Salento (Lecce) en 2010 y publicado en 2012.

Director de la investigación contenida en los dos volúmenes ahora reseñados, como lo fue anteriormente de la llevada a cabo por A. Manieri que ha servido de modelo de estos, y ella misma de atenta consejera, ha sido el reconocido especialista en poesía griega profesor Pietro Giannini, Ordinario Emérito de la Universidad del Salento (y ocasional colaborador del benemérito Prof. Bruno Gentili, a cuya escuela remiten de algún modo todos estos trabajos), a la cual universidad pertenecen los tres investigadores. Si el libro de Manieri, el más extenso de los tres, se ocupaba de los agones poético-musicales en el conjunto de la región de Beocia y sus diversos centros históricos, estos dos lo hacen, el uno (2. I Pythia di Delfi), a cargo de Maria Elena Della Bona y publicado en 2017, exclusivamente de los Juegos Píticos, los cuales, como cabe suponer dada su gran importancia, cuentan con testimonios suficientes, en este caso tanto literarios como epigráficos y alguno papiráceo, más o menos al $50 \%$, para producir un volumen de 305 págs. El tercer volumen (3. Sparta), publicado en 2018 a cargo de Flavio Massaro, se ocupa, en una extensión de 232 págs., de los agones poético-musicales de la ciudad eterna rival de Atenas, a saber las fiestas Carneas, las Gimnopedias y los agones paidikoí en honor de Ártemis Orthia, de los cuales las primeras cuentan con testimonios literarios y epigráficos, las segundas con testimonios exclusivamente literarios y los terceros con un testimonio literario y un buen número de dedicatorias a dicha diosa; y por último unos cuantos agones menos conocidos que cuentan con una serie de inscripciones en honor de intérpretes que intervinieron o vencieron en ellos.

Siguiendo el mismo esquema y orden del primero de los tres volúmenes, los dos ahora reseñados se componen, tras el índice, de un breve prólogo y una amplia introducción al tema objeto de estudio, mucho más amplia en el vol. 2 al centrarse toda ella en los Juegos Píticos, mientras que en el vol. 3 a la introducción general siguen luego otras parciales sobre las respectivas fiestas. Tras un breve conspectus siglorum sigue el grueso del trabajo, consistente en la relación y estudio de los correspondientes testimonios, empezando por los literarios y siguiendo con los epigráficos y papiráceos, allí donde hay de unos y otros. De cada uno de ellos se ofrece el texto, su traducción y su

4 "La actividad poético-musical de época helenística en las 'Vitae' de Plutarco", in A. Gostoli, A. Fongoni \& F. Biondi, Poeti in agoni, 451-74.

${ }^{5}$ F. Massaro, “Terpander: per un database degli agoni musicali greci”, in A. Gostoli, A. Fongoni \& F. Biondi, Poeti in agoni, 545-58 
comentario. Sigue al final la lista bibliográfica, precedida de un elenco de las correspondientes abreviaturas epigráficas, y se cierra cada volumen con tres índices: analítico, de fuentes literarias y de fuentes epigráficas, o epigráficopapiráceas en el vol. 2., los cuales son tan de agradecer en este tipo de estudios.

2. El Prólogo del vol. 2 (I Pythia di Delfi) (pp. 11-12) comienza por definir este agón de poesía y música, el más antiguo celebrado en Delfos, como la contrapartida en el panorama de la agonística musical, del festival de Olimpia en el ámbito de la agonística atlética, y por justificar su estudio desde el momento en que no existe otro que lo trate sobre la base de los testimonios antiguos, fuera de algunos artículos de comienzos del siglo pasado sobre determinadas fuentes epigráficas y un volumen sobre los juegos Píticos en época romana que contiene referencias a las fases precedentes ${ }^{6}$. $\mathrm{Su}$ originalidad estriba en que es la primera compilación de los testimonios literarios, epigráficos y papiráceos, desde su fundación mítica a su extinción, de los Pythia musicales, los cuales sirvieron de modelo para la institución de todas las competiciones poético-musicales de Grecia y de las regiones helenizadas.

La reconstrucción de los diversos aspectos de la competición que derivan de este estudio a través de sus abundantes testimonios es sintetizada en su amplia Introducción (pp. 13-92), precedida de un mapa de la Fócide tomado de la edición de 1965 (N.Y.) de la Descripción de Grecia VI de Pausanias, y su primera parte hace un recorrido por la historia del concurso. Entre otras cuestiones alude, por un lado, a los problemas relativos al mito, al año de la fundación y a los períodos sucesivos del agón y, por otro, a las características de la períodos de sedes agonísticas de la cual formaban parte los Pythia, aportando una posible solución a la presunta incongruencia de las fuentes al respecto. Sucesivos parágrafos de la Introducción analizan los datos de los testimonios en relación con diversos aspectos, del organizativo a los relativos a la época, lugar y categoría de los artistas admitidos a competir, con sus modificaciones a lo largo de los siglos. De los artistas se ofrece además el programa musical al que debían atenerse, centrado en el nomos pythikós, al cual es dedicada una amplia sección, y de la competición se aborda el aspecto de los premios, distinguiendo, según las épocas, la sustitución o la coexistencia de los tres premios previstos en Delfos: la corona de laurel, la palma y las manzanas. El último parágrafo trata de la prosopografía de los participantes en las ediciones de los Pythia de las que hay huella, catalogados en cómodas tablas por orden cronológico y con indicación de la respectiva procedencia, especialidad y fuente de referencia, destacando así los casos más significativos. Finalmente se analizan las fórmulas epigráficas utilizadas en época imperial para describir virtudes y honores de los competidores.

${ }^{6}$ R. Weir, Roman Delphi and its Pythian Games, Oxford 2004. 
La parte más amplia e importante del trabajo la constituye la sección que a continuación contiene los testimonios sobre los Pythia, su traducción y comentario, con tres partes, dedicadas a las fuentes literarias, epigráficas y tres testimonios papiráceos, respectivamente. En un primer momento se contaban 55 fuentes literarias más 42 epigráficas, cifra que de 97 ha pasado a 136, de ellas 70 literarias y 63 epigráficas, al decidir incluir algunos testimonios que al principio habían sido omitidos, la mayor parte decretos honoríficos que, sin mencionar explícitamente la participación en los Pythia del artista en cuestión, lo definen como periodonikes, esto es "vencedor del circuito" en el que se insertaba dicho agón. Las fuentes de cada grupo, recogidas en la mencionada database Terpander, son identificadas por la sigla de la sede agonal (Delph.) y una numeración correlativa siguiendo su orden cronológico. La procedencia de los testimonios literarios es por sí sola un reflejo de las épocas, obras y autores más interesados en el festival délfico, a saber: Pítica 12 de Píndaro, Helénicas de Jenofonte, Timómaco, Demóstenes (3 test.), Teócrito, Demetrio de Falero, Duris, Diodoro Sículo, Timeo, Estrabón, Estacio, Plutarco (Def. or.: 2 test.; Quaest. conv.: 5 test.; Lys.; Demetr.; Ps.-Plut. De mus.: 3 test.), Dión Casio (3 test.), Pausanias (4 test.), Luciano (2 test.), Clemente de Alejandría, Máximo de Tiro (2 test.), Póllux (2 test.), Ateneo (4 test.), Filóstrato (Vit. Apoll. 4 test.; Vit. Sophist. 3 test.), Eliano, Jámblico, Eusebio, Himerio, Libanio, Agustín, Jorge Sincelo, Proclo, Suda, Miguel Itálico, Antología Palatina, Escolio a Aristófanes Ach., Polemón, Escolios a Píndaro Pyth. (7 test.). De ellos los de Estrabón, Póllux 4, 84 y argumentum a de las Píticas de Píndaro son los tres testimonios más importantes, aunque a veces contradictorios entre sí, sobre la estructura del nomos pythikós, pieza clásica del repertorio de la aulética délfica que figuraba la lucha entre Apolo y la serpiente Pitón.

Si de los testimonios literarios no se indica la edición adoptada en cada texto, y creo que debería hacerse, así como incluir un aparato crítico selectivo en algunos casos, cada uno de los testimonios epigráficos y los tres papiráceos, con su correspondiente texto, traducción (estas todas de la autora a juzgar por el argumento ex silentio) y comentario, es precedido por una útil ficha que contiene su datación y lugar de procedencia, sus sucesivas ediciones, indicando con un asterisco la seguida en el presente caso, y los sucesivos trabajos que le han sido consagrados, como es habitual en el estudio de este tipo de textos. En el tiempo los testimonios se extienden a lo largo de unos seis siglos y medio, desde algo más de mediado el s. IV a.C. hasta casi finales del s. III d.C. Por su contenido, los más abundantes con mucho son los decretos o inscripciones (en algunos casos verdaderos epigramas) honoríficos, seguidos de los elencos de victorias y, a mucho mayor distancia, de dedicatorias a Apolo o a Zeus, entre otros textos, de artistas de las diferentes clases que intervenían en las competiciones: citarodos, arpistas (masculinos o femeninos), auletas, heraldos, komodoí, encomiógrafos, trompeteros, tragodoí, poetas, rétores, citaristas 
o pantomimos (aunque se duda de que los dos únicos posibles testimonios conocidos de este tipo se refieran también el agón pítico). Sin embargo el testimonio más antiguo y también el más espectacular lo constituye un texto propiamente literario aunque esté inscrito en piedra, que es el Peán a Dioniso (el primero dedicado no a Apolo sino a este dios, que con Apolo se reparte la tutela délfica tres meses al año), en doce estrofas (no todas conservadas) que suman dos columnas de 50 versos cada una, obra de Filodamo de Escarfia, según reza en el decreto honorífico contenido en la subscriptio del texto.

De las traducciones de los testimonios literarios, cuyo texto, traducción y comentario en este vol. ocupan casi tanto (pp. 95-175) como los de los testimonios epigráficos (pp. 177-268), unas indican el nombre del traductor y otras no, supongo que porque estas son obra de la autora del libro, aunque no lo he visto señalado ni tampoco sé cuál ha sido el criterio seguido en uno y otro caso. En todo caso las traducciones que se supone son obra de la autora, son cuidadas y ágiles, y apenas he encontrado alguna incorrecta: p.

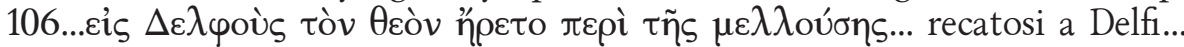
invocaba il dio per l'imminente...: interrogó al dios al dios sobre...; p. 133,

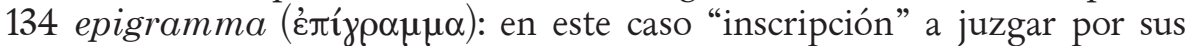
características: "esta tumba es del auleta Pitócrito, hijo de Calinico".

Los respectivos comentarios suelen explotar solventemente los datos de interés proporcionados por el testimonio, si bien en aquellos testimonios que comparten puntos en común -como la anécdota de la cigarra que con su canto suplió el fallo de una cuerda del instrumento del citaredo Éunomo de Locros (Delph. 11, 35), entre otros puntos- hay cierta tendencia a la reiteración a pesar del frecuente e inevitable uso de referencias cruzadas, reiteración que en ocasiones llega al extremo de repetir lo mismo en dos notas a corta distancia: p. 141 n. 1: 142 n. 1. Otros puntos discutibles son:

p. 111, "No está claro el motivo de por qué resultar el primero en el sorteo era para los citaredos la mejor suerte: probablemente era una cuestión de prestigio". Pero, si era resultado de la suerte, el prestigio no entraría en juego. De lo que no cabe duda es de que el primer puesto es el mejor en cualquier audición porque evita la comparación inmediata con el anterior o anteriores. Y también el último puesto puede ser el más lucido para aquellos ejecutantes confiados en su valía para superar al anterior y a la vez sin posibilidad de ser superados por el siguiente, como se deduce de Ar. Eccl. 1157ss.

p. 115, en el elogio de Estacio a su padre Papinio (Silv. 5, 3, 141ss.) la autora interpreta la referencia a las victorias obtenidas por este en los agones griegos como mérito proporcionado tanto por su prestigio como por la dificultad de enfrentarse a artistas de lengua griega. Pero hay que tener en cuenta que en esa época la lengua escolar por excelencia en Roma debía de ser todavía el griego y no el latín a juzgar porque aún en la segunda mitad del s. I d. C. Quintiliano (I 1,12-13) se queja de que no se comience a enseñar latín en la escuela a una edad más temprana. 
p. $160 \mathrm{n} .4$, se dice que de las diversas formas adoptadas por el nombre del auleta Antigénidas, como Antigenides y otras, la primera es apoyada por "la analogía de otros nombres tebanos como Pelopidas o Epaminondas, como "más tebana"": en realidad la verdadera razón es que son nombres beocios (frente al jónico-ático Antigénides) y por tanto tienen alfa larga, no eta, en el nominativo

p. 170, según la autora la secuencia de las acciones llevadas a cabo por Apolo a lo largo de los siete días representados en las siete partes de que consta el nomos pítico, sugiere la idea bíblica de la obra divina que se cumple en seis días y descansa el séptimo, pero no hay que olvidar que el siete es número y día consagrado a Apolo, por ser el de su nacimiento, que sepamos ya desde Hesíodo, Op.770s.; y este bien podría ser también el motivo de que la misma tradición mítica (Test. Delph. 64, Schol. in Pind. Pyth. Hypoth a Dr.) atribuya a Apolo (y no a Terpandro como se suele) el incremento del número de cuerdas de la lira de cuatro a siete.

p. 182, el comentario "es difícil conjeturar por qué razón los privilegios fueron extendidos a sus hermanos (los de Filodamo de Escarfia) y poco probable imaginar que los tres hayan condividido la misma arte y compuesto juntos el peán" está en contradicción con la reconstrucción del decreto honorífico de la inscripción, que eso es lo que dice precisamente, sin que la autora lo discuta.

p. 241, como ilustración de una inscripción honorífica única en su género, para un poeta periodonikés que fue "improvisador" en catorce ocasiones y demás, cita el caso de Quinto Sulpicio Máximo, poeta de 11 años ganador del concurso de improvisación, frente a 52 poetas, en los Juegos Capitolinos con el poema en griego, conservado en piedra, "¿Qué palabras diría Zeus a Helio para reprenderle por haber dejado a Faetón su carro?”, pero no indica que el tema es una ethopoiía, uno de los progymnásmata o ejercicios preliminares con que se introducía en la escuela el estudio de la retórica, como he contribuido a mostrar en un trabajo que la autora no $\mathrm{cita}^{7}$; de modo que a "improvisar poesía" se aprendía en la escuela greco-romana y había concursos públicos que favorecían este arte. Lo cual se puede poner en relación con test. 124 (p. 258), insólita inscripción honorífica de época imperial para un niño, "el primero entre los griegos y romanos en vencer en el agón pítico y otros con un encomio", género este que constituía otro de los progymnásmata, y también con test. 134 (p.270), otra inscripción honorífica, en este caso en su copia en papiro procedente de Oxirrinco (s. I d.C.), para un grammatikós (el

J. A. Fernández Delgado \& J. Ureña Bracero, Un testimonio de la educación literaria griega en época romana: IG XIV 2012=Kaibel, EG 618, Universidad de Extremadura 1991. 
profesor, digamos, de segunda enseñanza) "el primero entre los hombres dos veces periodonikes en poesía...y coronado en tragoidía”.

Por último, las abundantes citas de Moralia de Plutarco (ej. De frat. amore 492b (p. 101, n. 3); Quaest. conv. 704c (p. 116), p. 117, 118...) deberían llevar, como es la norma, letra mayúscula (...492B o mejor todavía...(Mor. 492B)).

De la amplia lista bibliográfica de este volumen solo me ha extrañado, desde un punto de vista puramente formal, que el lugar de edición, normalmente expresado en la forma propia de la lengua del ítem bibliográfico en cuestión, se exprese a veces en italiano (ej. J. Keil, Forschungen..., Vienna 1932; K. Ziegler, Plutarchi..., Lipsia 1964), o la forma de citar a G. Laguna Mariscal, Estacio...: Laguna Mariscal G., Estatio... Introducciòn, Editiòn Critica, Traducciòn...; desde el punto de vista de la bibliografía citada, la ausencia de S.-T. Teodorsson, A Commentary on Plutarch's Table Talks, 3 vols., Göteborg 1989-1996, el mejor comentario actual sobre las Quaest. conv. de Plutarco, obra que la autora utiliza ampliamente.

Erratas apenas se encuentran, en un libro con tantas referencias: p. 107 ...riprende la narrazione dei vv. 267ss. dell' Odissea: falta la referencia al canto (III); p. 113 da Póllux Onom. 4, 84 como una de las tres fuentes más importantes sobre la estructura del nomos pythikós, pero en el Índice Póllux no aparece recogido; p. 129 Haward por Howard: p. 137 n. 15 Tatian. Adv. Greac., en vez de Graec.; p. 147 n. 5 Amarant. fr. 2 Garcia Lazaro, en vez de García Lázaro; p. 159 el auleta Antigénidas (Antigenidas it.) es llamado Antigenida en n. 2. Griego: p. 116 غ̇ंì K $\alpha \lambda \lambda \imath \sigma \tau \rho \alpha ́ \tau o v$, en vez de -ov; p. 146

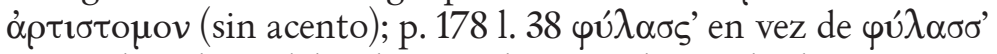

3. El prólogo del vol. 3 señala cómo la amplia literatura existente sobre la historia y cultura de Esparta, la eterna rival de Atenas, ha impuesto al presente estudio de sus agones musicales una selección del material, que se limita a los testimonios relativos a los agones espartanos y prescinde de los de otras localidades de Laconia, incluido el festival de la Jacintias, caracterizado por afamadas performances musicales pero sin testimonio explícito de un componente agonal. Dichos testimonios se dividen en cuatro grupos, correspondientes a los respectivos capítulos del libro: los dos primeros relativos a los agones de las Carneas y Gimnopedias, considerados entre los agones poético-musicales documentados más antiguos no solo de Esparta sino de Grecia, y atestiguados sobre todo en fuentes literarias; los llamados agones paidikoi, celebrados en las fiestas en honor de Ártemis Orthia y documentados en numerosos testimonios epigráficos sobre todo de época imperial pero que parecen tener un origen más antiguo; más los testimonios relativos a los festivales de época imperial. Las fuentes, con su traducción y por orden cronológico en cada sección, precediendo siempre las fuentes literarias a las epigráficas (de las cuales la edición de referencia es señalada con un asterisco), son seguidas de un comentario dedicado a su contextualización 
y a las cuestiones exegéticas que suscitan, en algunos casos siendo el texto griego, aquí sí, acompañado de un aparato crítico selectivo que da cuenta de variantes textuales o de conjeturas significativas.

La Introducción general al volumen (pp. 15-41 incluido al final un ilustrativo plano de Esparta tomado del fundamental estudio de P. Cartledge, Sparta and Lakonia: A Regional History 1300-362 B.C., London-N. Y. $2002^{2}$ ) contiene un cumplido resumen de la historia cultural de Esparta que intenta abrirse paso entre el carácter con frecuencia tendencioso, filo o antiespartano, de las fuentes. Entre estas están, para la época arcaica, la informaciones proporcionadas por la poesía de Tirteo y Alcmán más las ofrecidas por el material arqueológico y epigráfico, las cuales han puesto de manifiesto una sociedad expuesta a importantes cambios en su estructura económica, política, social y cultural no solo en el paso de la época arcaica a la clásica sino también en el período helenístico y romano, sobre los cuales ha habido importantes contribuciones en los últimos años. Rodeada de imponentes cadenas montañosas, entre las cuales destacaba el monte Taigeto, la ciudad se erigía en una especie de fortaleza natural que protegía a sus habitantes sin necesidad de murallas, al menos hasta la época helenística, y en el s. VI a.C. dominaba un territorio que entre otras regiones comprendía, además de la llanura de Laconia, la de Mesenia, ambas fértiles, más la isla de Citera.

Aparte del protagonismo que en la Ilíada ostentan Helena y Menelao, los reyes de la Esparta aquea, el Catálogo de las Naves (Il. II 581) menciona Esparta entre los burgos que formaban parte de Lacedemonia, nombre ya atestiguado en las tablillas en lineal B y usado por Homero para indicar toda la región pero a veces también la capital de Laconia. Posteriormente el llamado "retorno de los Heraclidas", a cuyo éxito contribuyeron las tropas dorias, constituyó un eficaz instrumento de afirmación cultural de los espartanos en suelo laconio. La constitución espartana, llamada Rhetra, fue el fruto de un largo y complejo proceso y se basaba en una equilibrada división de poderes entre los dos reyes, la gerousía y la asamblea del pueblo o apella, siendo la base de la actividad política el damos "pueblo", de ideología aristocrática y compuesto por los privilegiados terratenientes espartanos, que reinaban sobre la masa de los ilotas, habitantes esclavizados de las tierras conquistadas por los espartanos, y sobre la restante población de Laconia, los periecos, que formaban parte del ejército pero no gozaban de derechos políticos. Todo ello propició el temprano desarrollo de una cultura refinada, potenciada por los frecuentes contactos externos. La arqueología ha puesto de manifiesto progresos significativos en la producción artesanal -la cerámica, costosos ex votos en el santuario de Ártemis Orthia, manufacturas orientalizantes en bronce procedentes de toda Grecia, la arquitectura y la escultura- a partir de la primera mitad del s. VIII a.C. Otra señal importante de la atención de Esparta a las relaciones internacionales es la participación en las Olimpiadas, 
en las cuales sus hombres destacaron ampliamente, sobre todo entre el final de la primera guerra mesenia y los primeros decenios que siguieron a la segunda (final del s. VIII-segundo cuarto del s. VII). Contra ello se pronunció Tirteo (fr. 9, 1-14 Gentili-Prato) contraponiendo la atención al valor guerrero al excesivo afán de la gloria deportiva.

También en el campo de la mousiké la cultura laconia se muestra dinámica y abierta a influencias externas, sobre todo en el período de relativa tranquilidad que siguió al final de las guerras mesenias (a mediados del s. VII a.C.), en el cual Esparta se afirma como centro cultural de primer orden y foco de atracción de numerosos músico-poetas extranjeros, como atestigua el tratado De musica pseudoplutarqueo, del citarodo Terpandro de Lesbos, líder de una primera "escuela" musical estrechamente ligado a la historia de las Carneas, a diversos poetas de otras regiones vinculados a las Gimnopedias, como Tales de Gortina o Sácadas de Argos entre otros. Tal concentración de artistas fue sin duda propiciada por la institución de agones en la incipiente formación de la polis y el proceso de progresiva renovación musical en el ámbito de las fiestas religiosas. Si bien las fuentes no ayudan a reconstruir un cuadro claro de la organización de estos, sí se pueden identificar especialidades de los artistas participantes en las Carneas y las Gimnopedias. La primera de estas fiestas ostenta la primacía de los agones citaródicos, uno de los primeros géneros representados en los concursos musicales y al cual se encomendaba el relato de los antiguos mitos, en clara rivalidad con la performance rapsódica. Los mitos desempeñaban también un papel relevante en las ejecuciones de los coros, en cuyas danzas destacaban los espartanos (piénsese por ejemplo en la famosa danza pírrica, de carácter militar), siendo visible su conexión con el culto en repertorios de cerámica provenientes del santuario de Amiclas y de máscaras de arcilla del de Ártemis Orthia. Particularmente célebres fueron los coros de las Gimnopedias (de cuyos “danzantes desnudos” tomaron el nombre) y las Jacintias, ambas conectadas, como las Carneas, con el culto apolíneo y en cuyo contexto las melodías y textos de los líricos más representativos de la música espartana pasaron a formar parte del repertorio tradicional, destacando entre ellos el nombre de Alcmán y sus partenios, destinados a ser danzados por coros de muchachas, tal vez en competición con otros.

En medio de la alegría de la música y el espectáculo, en las fiestas Esparta mostraba las competencias músico-corales de sus ciudadanos, como indica Ateneo $(4,139 \mathrm{~d}-\mathrm{f})$ en un interesante testimonio de época anterior acerca de la implicación de la entera comunidad en la atmósfera de la fiesta, las Jacintias en este caso. En este ámbito los músicos podían perfeccionar su arte, enfrentándose en los agones con profesionales procedentes de otras partes del mundo griego, al tiempo que la polis recibía de los artistas extranjeros un estímulo en la construcción de su propia identidad cultural. Como en otras comunidades griegas, también en Esparta la música acompañaba diferentes momentos de la vida cotidiana: podía servir para infundir valor guerrero o 
para acompasar el paso de la marcha, como en los embateria de Tirteo, o bien para acompañar, en paz, las ejercitaciones gimnásticas, las manifestaciones religiosas y los banquetes. La música constituye un extraordinario medio de expresión en un contexto cultural de comunicación oral cual es el laconio, en el cual se desarrolló al mismo tiempo una clara conciencia de la eficacia del silencio y de la expresión braquilógica; canto y danza servían de refuerzo a la propia cohesión política y social, como pone de manifiesto Plutarco en la Vida de Licurgo $(14-22 ; 25,3 ; 27,5)$, según la cual en las ejecuciones musicales se ponía en funcionamiento la competición, con juicios de aprobación o de censura con respecto a los propios ciudadanos.

Sin embargo, frente a este cuadro, la tradición trasmite una imagen diferente de Esparta, hostil a las novedades culturales y hasta a la propia música, como se deduce de las anécdotas recogidas en los Laconica apophthegmata del corpus plutarqueo de Moralia, las cuales muestran esa doble cara de la cultura espartana, considerada un baluarte de la música aristocrática, cuando no una amousos ciudad-cuartel, frente a los alardes de la nueva música acometidos en particular por el teatro ateniense. Las distintas representaciones de la cultura musical espartana, no obstante, revelan una realidad histórica in fieri, que es la de los importantes cambios que allí tuvieron lugar hacia la mitad del s. VI a.C. convirtiéndola en una polis austera, indiferente a los progresos culturales y adversa a los artistas innovadores. Semejante decadencia se observa también en la cerámica, la arquitectura y en una menor presencia de Esparta en las victorias olímpicas, así como en los importantes cambios que tuvieron lugar en su política tanto exterior como interior, si bien la actual historiografía considera más probable un desarrollo progresivo de características ya presentes en época anterior, que un corte neto entre la brillante Esparta permeable del s. VII y la cerrada Esparta posterior. A ello hay que añadir otros factores que contribuyen a acentuar esa sensación de transformación: la concurrencia de otros centros culturales surgidos en el s. VI como Delfos o Atenas y la contraposición ideológica entre Esparta y Atenas, que ha dejado una huella indeleble en la historiografía, empezando por Tucídides. En todo caso, la transmisión de los textos poéticos fue confiada durante mucho tiempo no a la escritura sino al reúso de las composiciones ya sea en los agones ya en contextos simposiales, en los cuales, y no solo en festivales como las Jacintias o las Gimnopedias, eran reejecutados los cantos de los líricos. Por lo demás, la documentación literaria y epigráfica atestigua una cierta riqueza de festivales en época clásica que ponían a prueba la habilidad deportiva y musical de los espartanos, como atestigua sobre todo la inscripción de Damonon, de entre finales del s. V y comienzos del s. IV a.C., consistente en dos fragmentos de una estela de mármol, uno de ellos hallado entre los restos del templo espartano de Atenea Chalkioikos, con un elenco de las numerosas victorias ecuestres y pedestres del dedicante y su hijo en el entorno de la región de 
Laconia, dos de cuyos agones al menos (Eleusinia y Parparonia) incluían también ejecuciones artísticas (citarodia y coros respectivamente).

Las fuentes concernientes a la cultura musical de Esparta en el período posclásico, al menos hasta época romana, son escasas y poco fiables, debido a la carga ideológica de los textos, la mayor parte literarios, marcando la derrota de Leuctra (371 a. C.) el comienzo de su declive histórico, si bien el s. III significó la salida de su aislamiento cultural y su transformación en un centro helenístico ${ }^{8}$. La documentación es más rica en el período sucesivo, en que, tras la derrota de la Liga Aquea en el 146 a.C. a manos de los romanos, estos la convirtieron en una "ciudad libre" naturalmente bajo su órbita y por Pausanias se sabe de algunos agones de carácter local en su época que indican la recuperación de las tradiciones espartanas y la conservación de una cierta identidad. Concretamente en el santuario de Ártemis Orthia tenían lugar agones efébicos que comprendían pruebas físicas pero también concursos musicales (una parte de los llamados paidikoi agones) cuyos vencedores recibían un premio y tenían la posibilidad de dedicar una estela con su nombre, señal del papel del agonismo y la vitalidad de la cultura musical en la paideia espartana. Por otra parte, los agones de época imperial, atestiguados sobre todo en el s. II, reflejan profundos cambios en la historia de Esparta, que devino muy semejante, también desde el punto de vista urbanístico (con presencia de gimnasios, termas...) y arquitectónico (un gran teatro en piedra, todavía visible, que sustituyó al de época helenística), a las demás poleis de su tiempo y asumió un papel de primer orden entre los centros culturales del mundo griego, incluida la presencia de agonistai (actores, citarodos, auletas, poetas, pantomimos y rétores además de atletas) extranjeros y de antiguas y nuevas fiestas que a los cultos antiguos unían el del emperador, aproximando de este modo a Esparta a sedes agonísticas del Peloponeso como Olimpia, el Istmo o Nemea que formaban el circuito a completar por los agonistas aspirantes al título de periodonikes.

4. Los cuatro capítulos del libro, dedicados a la compilación y comentario de los diversos testimonios sobre las fiestas espartanas y precedidos cada uno de su introducción, ocupan las pgs. 45-204 y de ellos el primero (2.) está dedicado a las Carneas. Su introducción atiende a las características generales de la fiesta y a los agones en sí, haciéndose puntual y detallado eco de las aportaciones arqueológicas allí donde procede. La fiesta estaba dedicada a Apolo Carneo, culto no exclusivo de Esparta sino practicado en todas las comunidades dorias, cuya representación del dios en forma de ariete sugiere la superposición a una divinidad más antigua y de cuyos orígenes Pausanias refiere diversas tradiciones de las cuales se pueden deducir connotaciones mánticas del santuario y origen predorio del culto. De los testimonios de las fuentes también se puede deducir que la fiesta se celebraba en un arco temporal

${ }^{8}$ Cf. Fernández Delgado \& Pordomingo cit. supra n. 3, sobre su actividad poético-musical. 
que abarcaba del día 7 al 15 del mes Carneo, mes sagrado para los espartanos y para los dorios en general, y estas fechas pueden oscilar entre el fin del verano y el comienzo del otoño. Aunque lacunosos, los testimonios literarios se compensan entre sí sobre algunos eventos que caracterizaban la fiesta: una carrera ritual de jóvenes, llamados staphylodromoi ("corredores del racimo de uvas", supuestos estimuladores de los vendimiadores y de buen presagio para toda la comunidad), un banquete de ciudadanos adultos (rito conectado con las syssitia, las comidas comunales espartanas, y representación por tanto de una fiesta militar), agones musicales y tal vez deportivos. Precedidas durante el verano de las Jacintias y las Gimnopedias, las Carneas parecen suponer la conclusión de un ciclo de fiestas apolíneas centradas en ritos de iniciación. Junto a los ritos religiosos e iniciáticos un papel central en la fiesta parecen haber desempeñado los agones, musicales y tal vez deportivos según podría deducirse de una inscripción votiva del s. VI a.C. La fundación de los agones musicales parece tener que ver con la actuación de Terpandro de Lesbos de acuerdo con las fuentes literarias. Un género de la citarodia era el nomos, que Terpandro renovó y perfeccionó, dividiéndolo en siete partes con secciones de melodía y contenido autónomos, al tiempo que aumentó de cuatro a siete las cuerdas de la fórminge e introdujo el bárbitos, un tipo de lira propio del contexto convival, impulsando en particular el género de la citarodia épica en el ámbito de los agones espartanos. Y al prestigio de las carneas contribuyeron, tras Terpandro, otros renombrados artistas reconducibles al mismo ambiente cultural en el que aquel se había formado, según parece poder interpretarse el refrán "después del cantor de Lesbos", conocido ya por Cratino y luego por la Constitución de los Lacedemonios de Aristóteles y por el tratado De sera numinis vindicta de Plutarco. Por lo demás, todavía en el s. V a.C. conservaban las Carneas su antiguo poder de atracción sobre los músicos extranjeros, de acuerdo con ciertas fuentes literarias, y ello a pesar de la firme resistencia de las autoridades culturales a las novedades musicales de los artistas coetáneos. Por lo que respecta al lugar de la fiesta y los agones, Pausanias $(3,13,3)$ señala la existencia en Esparta de dos santuarios dedicados al Carneo, uno de ellos, el más antiguo, situado en un área rica en monumentos de gran importancia para la vida religiosa de Esparta, entre ellos la Skias, el cual se supone conectado con el agón musical. No se tienen noticias de las Carneas en el s. IV y en época helenística, pero hay testimonios epigráficos que demuestran su supervivencia todavía en época romana.

Los testimonios literarios sobre las Carneas provienen de Helánico (ap. Athen. 14, 635e) y Julio Africano (ap. Crónica de Eusebio) (ambos sobre la fundación de la fiesta y la primera victoria de Terpandro), Alcestis 445 ss. de Eurípides (sobre la equiparación en importancia de los agones poéticomusicales de las Carneas con los festivales de Atenas), De musica de Filodemo (sobre el "encanto" de los espartanos ante la música de Terpandro en dicha 
fiesta), Instituciones Laconias 238C de Plutarco (sobre las sanciones de los éforos a Terpandro y luego a Timoteo de Mileto en las Carneas por salirse de los cánones de la antigua música introduciendo en sus liras más cuerdas de las permitidas), De musica 6 pseudoplutarqueo (sobre el último citarodo lesbio vencedor en las Carneas, escuela a partir de ahí interrumpida), Escolios a Aves 11 (sobre Execéstides, citarodo vencedor en el agón Pítico, en el de las Carneas y dos veces en el de las Panateneas, todavía famosos en el s. V a.C., y por otra parte frecuente objeto de burla por parte de la comedia como extranjero, poeta errante esclavo y Cario) y 1403 de Aristófanes (sobre los primeros organizadores, Laso de Hermione o Arión de Metimna, de coros cíclicos, o ditirambógrafos), y los dos testimonios epigráficos consisten en un plato de bronce votivo (supuestamente recibido como premio) del Heraion de Argos, del s. VI a.C., y una estela de mármol del s. I a.C., el testimonio más tardío sobre el agón, con un catálogo de sitethentes, esto es participantes en un banquete anual a expensas del estado: 31 hombres y dos mujeres, seguidos de un título o función, entre ellos un vencedor en las Carneas. Tanto en este como en los sucesivos capítulos dedicados a las fiestas, las traducciones, que por defecto hay que suponer que son propias, son claras y atinadas, y los comentarios sacan todo el jugo posible a lo escueto de los textos.

El segundo capítulo (3.) está dedicado a las Gimnopedias y su introducción trata de las características generales de la fiesta y de sus cantos y sus danzas. Según Pausanias y otras fuentes la fiesta gozaba en Esparta de la máxima consideración y con las Jacintias son símbolo de la pasión espartana por las celebraciones religiosas y musicales, en particular los coros y danzas, de modo que su alegre atmósfera y la concurrencia de visitantes y extranjeros hacían de ella la fiesta por excelencia. Sin embargo, a pesar de su importancia, las informaciones que se pueden recabar de las fuentes, en este caso exclusivamente literarias, son muy fragmentarias y problemáticas, empezando por la dificultad de determinar el culto asociado a la fiesta, siendo considerada una especie de ceremonia semirreligiosa en que los coros de danza y música, su principal componente, desempeñaban un papel central, en conmemoración de algún acontecimiento histórico; su propio nombre, lejos de evocar, como en el caso de las Carneas o las Jacintias, el de una divinidad a la que esté dedicada, parece

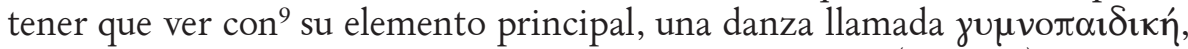
tal vez ejecutada por $\pi \alpha \tilde{i} \delta \varepsilon \varsigma$ o por danzantes en general ( $\pi \alpha i ́\} \varepsilon v v)$ desnudos ( zupvoí). Su fundación podría remontarse al s. VII, unos años después de la de las Carneas según la Crónica de Eusebio, pero el pseudoplutarqueo De musica menciona nombres de artistas de época posterior y de diversos géneros, como Tales de Gortina, lo cual permite reconducir el festival al ámbito de la lírica coral, concretamente al peán, pero incluyendo otros géneros poéticomusicales

\footnotetext{
${ }^{9}$ No referirse a, como dice el autor, p. 82.
} 
como la aulodia y la aulética. La fiesta parece que se celebraba en verano, duraba al menos tres días y las performances tenían carácter agonístico, aunque nada sabemos de vencedores en la misma. Del mismo modo, fuentes y autores vacilan en cuanto a la composición de los coros (jóvenes/ y hombres) y al lugar (teatro o ágora) de sus ejecuciones, como vacilan en cuanto a la naturaleza de estas. Fuentes eruditas más o menos basadas probablemente en Sosibio, la fuente principal (a través de Ateneo), definen las Gimnopedias como una fiesta en la que se ejecutaban cantos corales (a veces se especifica "peanes"), supuestamente centrados en los acontecimientos principales de la historia de Esparta, en memoria de los soldados que combatieron en la Tireátide, región permanentemente en litigio entre Esparta y Argos; dichas ejecuciones tenían la función de consolidar en la comunidad espartana valores transmitidos de generación en generación, ocupando los jóvenes el centro de este proceso educativo.

Los testimonios son 14 y proceden de: Heródoto VI 67 (sobre un suceso histórico ocurrido durante la celebración de las Gimnopedias y sus implicaciones acerca de estas); Helénicas 6, 4, 16 de Jenofonte y Agesilao 29 de Plutarco (con datos sobre la fiesta, el lugar de celebración, el agón coral y el coro de hombres (al menos en época clásica) y el papel de los éforos en su desarrollo, en plena derrota espartana en Leuctra); Diógenes de Babilonia ap. Filodemo, De musica (mencionando diversos tipos de danza coral, entre ellos la gimnopédica); Sosibio ap. Athen. 15, 678 b-c (problemático testimonio sobre los coros que celebraban la victoria Tireátide en las Gimnopedias, su composición, de jóvenes y hombres desnudos, y los autores de sus cantos) y definiciones de las Gimnopedias más o menos derivadas de aquel por parte de 14 lexicógrafos distintos, desde Frínico al paremiógrafo Apostolio (que insisten en algunos de estos mismos detalles); Instituciones Laconias 208D de Plutarco (anécdota sobre el puesto asignado a alguien en el coro de las Gimnopedias); Pausanias 3, 11, 9 (sobre el ágora como emplazamiento del coro de efebos en las Gimnopedias); De musica pseudoplutarqueo (sobre las Gimnopedias, entre otras fiestas peloponesias con coros posiblemente iniciáticos, como parte de la segunda fundación musical en Esparta y los poetas líderes de esta, de Tales de Gortina a Sácadas de Argos); De saltatione de Luciano (sobre las gimnopedias en comparación con otras danzas laconias de formación militar de los jóvenes); Máximo de Tiro 35 (mención de las Gimnopedias en primer lugar entre otras fiestas espartanas y al lado de otros famosos festivales griegos, como contraejemplo del sentido de amistad y no de discordia que debe presidir la verdadera tregua que conlleva la fiesta) y Ateneo 14, 631 b-c (mención de la gimnopédica como danza gimnástica previa a la pírrica antes de entrar en el teatro, según el controvertido testimonio de Aristóxeno).

El capítulo que ocupa más páginas del libro (115-170) es el dedicado a los paidikoi agones en honor de Ártemis Orthia (4.), si bien hay que 
tener presente que la totalidad menos uno de sus 62 testimonios son breves inscripciones dedicatorias a la diosa, muchas de ellas fragmentarias, que el autor del libro dudó al principio si incluirlas en este. Dichas inscripciones, expone la Introducción al capítulo, se refieren a competiciones al menos en parte musicales a cargo de muchachos y fueron encontradas la mayoría en los primeros años del s. XX, en el santuario de la diosa situado en la localidad espartana de Limnaion, cuyo templo era sede de un culto arcaico vinculado a los ritos de iniciación, demostrando así, como en el caso de las Gimnopedias, la estrecha relación entre agones musicales y formación de los jóvenes. Las inscripciones utilizan un dialecto de rasgos muy arcaicos, que sin duda contribuía a dar vida a la Esparta de antaño, y se hallan en estelas erigidas en agradecimiento a la divinidad por victorias obtenidas en competiciones probablemente conexas con una fiesta en su honor. Menos una, del s. IV a.C., las demás son de época romana, de entre el final del s. II a.C. y el s. III d.C., perteneciendo en su mayor parte a los s. I-III d.C. Acompañaba a la inscripción una hoz de hierro, premio de la competición de significado discutido. Los paides participantes en los agones debían de ser, a juzgar por ciertas glosas a textos de Heródoto y Estrabón, efebos espartanos de entre 14 y 19 años. Todavía más problemática es la determinación de la naturaleza de las competiciones, para cuyas especialidades las inscripciones proporcionan diversos nombres que al menos en dos casos probablemente se pueden identificar con agones musicales, con primacía del canto, y estos de carácter individual y no colectivo, coral, como se pensó en otro tiempo, sin perjuicio de la inclusión de duras pruebas físicas que recordaban el antiguo adiestramiento militar de los espartanos. Las fuentes sobre los paidikoi agones confirman pues cómo todavía en los s. II y III d.C. la mousiké debía de contribuir en gran medida a una función no secundaria de la agogé espartana cual era la conservación de la identidad cultural cuando la supremacía política de los lacedemonios no era ya más que un lejano recuerdo. Sigue un extenso y útil cuadro sinóptico de los vencedores en las especialidades musicales de los paidikoi agones, organizado por fuentes, vencedores, épocas, especialidades y otras especificaciones.

De los testimonios, el único literario es una glosa de Hesiquio sobre el tipo de canto llamado $\mu \tilde{\omega} \alpha$, forma lacónica de Moũ $\sigma \alpha$ atestiguada ya en Aristófanes, sin que se pueda establecer una relación directa entre la glosa y la especialidad musical presente en las inscripciones espartanas. De las dedicatorias de victoria a Ártemis, básicamente cortadas por el mismo patrón, en que consisten las 61 breves inscripciones estudiadas, con su traducción y comentario, los principales datos pertinentes se hallan recogidos en el cuadro sinóptico mencionado, otros datos de interés conciernen básicamente al vocabulario de las especialidades musicales y a sus componentes. De ellas la 2 (s. IV a.C.), la 6 y la 8 están en dísticos elegíacos, la 5 está la primera parte en prosa y la segunda en dísticos, la 8 consta de tres versos isopsefos, la 
parte conservada de la fragmentaria 4 podría encajar en un ritmo dactílico, aunque el autor no haya reparado en ello ni haya prestado tampoco atención al porqué de la presencia de la métrica y a su propio estilo y lengua, sobre todo en las inscripciones de época tardía.

Junto a los festivales y agones tradicionales, todavía vigentes en época romana, a partir del s. I d.C. surgen en Esparta nuevas fiestas y concursos deportivos y musicales con capacidad de atraer participantes de lejos, como se sabe sobre todo por las inscripciones honoríficas que constituyen la mayor parte de los 12 testimonios aducidos, todos epigráficos, los cuales, dentro de sus límites numéricos y tipológicos, permiten (cap. 5. del libro) bosquejar su trayectoria desde la época de Augusto hasta al menos el comienzo del s. III. A la época augústea parece remontar ya el festival Kaisareia, probablemente fundado por el espartano G. Julio Euricles, apoyo del césar y del culto imperial en Esparta y promotor asimismo de la reedificación del costoso teatro, único indicio de la presencia de concursos musicales en un festival bien conocido por los deportivos. En el s. II fueron instituidos nuevos agones, algunos de relevancia internacional y con competición musical incluida, como corresponde a la renovación cultural de la zona oriental del imperio llevada a cabo por los Antoninos. El más antiguo es el de los Ourania, cuyo nombre evoca un antiguo culto a Zeus atestiguado por Heródoto y tal vez sea refundación de una anterior fiesta laconia debida a Nerva o a sus herederos Trajano o Adriano. Las inscripciones honoríficas que registran el curriculum de atletas y músicos participantes, demuestran el prestigio internacional de los agones y dan idea de sus diversas especialidades, según resume el cuadro ofrecido con los datos de los cinco vencedores conocidos en el agón deportivo y los tres del agón musical (un tragodós, un auletés y un citarodo) en la primera mitad del s. II, la mejor atestiguada al respecto. De época poco posterior a la de las Ourania es la fundación del agón de las Leonideia, parte de un festival anual en el que, mediante competiciones deportivas y de oratoria, se conmemoraba a los héroes de las Termópilas y de Platea, sin duda ya desde antes del s. II a juzgar por el texto de una inscripción que informa también sobre sus especialidades deportivas y categorías de edad. En el último período del reinado de Adriano fue instituido otro agón de resonancia internacional, el de las Eurikleia, cuyo nombre deriva de un descendiente del probable fundador de las Kaisareia, un benefactor de su ciudad honrado por ello con dicha fiesta, de la cual se atestiguan solamente agones deportivos y no musicales. Entre las fuentes sobre agones musicales espartanos de época imperial es de particular interés una inscripción fragmentaria en bronce (SEG XI 838: test. AR 4), hallada en torno al teatro, que contiene el estado de cuentas de un agonoteta especificando las sumas pagadas a los vencedores en diversas especialidades agonísticas, tanto musicales como deportivas, desde los trompeteros y heraldos a los encomiógrafos y hasta una de pintores, incluidos los nombres y la patria de cada uno, de un importante festival 
datable en los años cuarenta del s. II, del cual sin embargo no consta el nombre, aunque se supone ha de ser uno de los importantes de la época, Ourania o Eurykleia. Hacia el fin del s. II Esparta conoce la fundación de otro festival importante, de la categoría sacro y pentaetérico, los (Olympia) Kommodeia, de Commodus, que contemplaba agones deportivos y musicales y a través del culto al emperador estaba asociado al de Zeus Olympios, de donde su denominación completa. Con el de los Ourania este es, pues, el único de los importantes festivales espartanos, dentro de la explosión agonística que en general caracterizó a aquel período de la cultura griega, en el que se atestigua con certeza la presencia de agones musicales; no obstante, hay testimonios epigráficos que señalan genéricamente Esparta como el lugar en que los artistas han obtenido la victoria u otros honores, como la ciudadanía o una estatua; todos ellos son resumidos por el autor en un cuadro (p. 183) que define muy bien su vitalidad cultural en esta época, incluido un arte tan poco esperable en la austera Esparta de antaño como es la pantomima.

Los testimonios aducidos, doce y todos epigráficos, con sus pertinentes traducciones y comentarios, son: tres decretos honoríficos sobre un tragodós, un auleta y un citarodo vencedores en el festival de Ourania, el mencionado estado de cuentas de un agonoteta de este festival o del de Eurykleia, una inscripción honorífica sobre un poeta vencedor en el festival de Olympia Kommodeia, dos inscripciones sobre victorias en agones no especificados, de ellas una inscripción honorífica sobre un auleta y otra sobre un citarodo; y cinco inscripciones sobre posibles vencedores en agones espartanos, a saber, un decreto honorífico sobre un encomiógrafo, otra inscripción honorífica sobre un pantomimo, una dedicatoria a Apolo Pítico y una dedicatoria de una estatua a un auleta, más una inscripción fúnebre.

La bibliografía presenta aparte una útil sección de abreviaturas epigráficas, como el anterior volumen, y la lista restante es amplia, necesariamente variada y bien integrada, con la excepción de algún título citado y no recogido en la lista final: Zanetto 1987, p. 72 n. 2; una cierta inconsistencia en la utilización de mayúsculas y minúsculas en los títulos en inglés (tipo T. C. Power, The culture of kitharoidia) o alguna falta tipográfica (H.ColLitz-F.Bechtel, p. 203).

Muy contados son en todo caso los fallos observados. En algunos casos el autor no da el nombre del traductor del texto citado, sin que sepamos tampoco si es él mismo: p. 25, Ateneo 4, $139 \mathrm{~d}$-f sobre las Jacintias; p. 28 n. 2, Xen. Resp. Lac. 4, 2; p. 53, Anth. Pal. 9, 488; p. 55 n.1, 2, 6, que a juzgar por su indicación en p. $56 \mathrm{n} .2$ sospechamos que pueden provenir de los testimonios de Gostoli sobre Terpandro; p. 58 n. 1 Plut. Agis; p. 81 n. 4, Xen. Mem., Plut. Cim.; p. 84, Plut. Lic.; p. 85 n. 4 Tuc.; p. 93 Hdt.; p. 94 Xen. Hell., Plut. Ages.... Letras minúsculas en lugar de mayúsculas para señalar la paginación editorial de Moralia de Plut.: p. 28 n. 3, etc. Apophth. Lac. 239b...; p. 59 n. 6, 67 Inst. Lac. 238c; p. 63 n. 3 Ps. Plut. Mus. 4, 1132 d-e; p. 68 Inst. Lac. 
238 a-c, n. 2 Apophth. Lac. 216 c; p. 69 n. 4; p. 103; p. 95 n. 5; p. 103 y n. 3

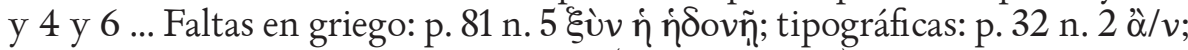

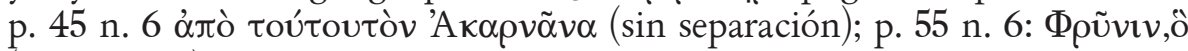
(sin espacio). Algunas traducciones son mejorables: p. 95 n. 5 "...collocato

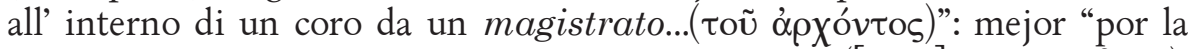

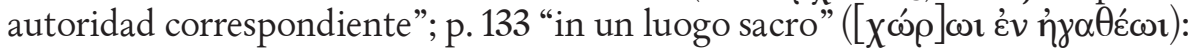
creo que mejor "en su sagrada sede" tratándose del lugar de la victoria cuyo trofeo es dedicado a Ártemis; p. 172 avendo vinto tra i giovani imberbi nella lotta: creo que mejor "habiendo vencido en la lucha entre jóvenes imberbes".

5. A modo de conclusión, digamos que toda esta riqueza de festivales músico-literarios en competición y circuito a través de las diversas regiones de Grecia, multiplicados en época imperial por todo el mundo helenizado, por parte de numerosos artistas y comprendiendo variados géneros, empezando por el nomos pítico, cuya temática se hacía eco del sentido del festival délfico, más otras formas de citarodia, aulética y aulodia, a base de los correspondientes instrumentos de viento y de cuerda y a cargo a veces de mujeres o de niños, además de otros géneros poéticos, teatrales, de encomio en prosa, de heraldos y trompeteros, de pantomimos..., que se extrae de los testimonios a lo largo de los siglos, muestra una cara de la antigua cultura griega menos conocida y sin embargo no menos importante desde el punto de vista del nivel que la caracteriza; con la diferencia de que refleja una efervescencia cultural viva, no solo libresca, y con tal participación popular como no ha conocido jamás pueblo alguno. Solo así se explica algo que siempre ha llamado poderosamente la atención de los estudiosos, a saber, que el público de los grandes espectáculos culturales griegos, de la lírica coral a la tragedia, la comedia o el drama satírico, pudiese apreciar las frecuentes alusiones o juegos intertextuales contenidos en sus textos con respecto a los diversos géneros literarios, empezando por Homero, cuando mayoritariamente se trataba de un público iletrado; porque en las numerosas fiestas locales y sus variadas competiciones músico-literarias encontraban una fuente de formación viva y de reelaboración permanente de mitos y de historias que podían suplir a los proporcionados por un tipo de formación escolar inexistente. Todo esto permiten vislumbrar los volúmenes reseñados, sin contar la enorme cantidad de detalles técnicos, artísticos, organizativos, políticos, religiosos, míticos, históricos, etc., sobre los diversos agones musicales griegos, los espartanos en este caso y muy en particular el festival artístico-religioso más importante de Grecia a lo largo de los siglos, el agón pítico, que los testimonios literarios y epigráficos proporcionan y los autores de estos libros explotan oportunamente y con esmerado rigor filológico e histórico-literario. 